\title{
Species and prevalence determination of Human Intestinal Parasites among Patients attending two Medical Centers in Yola, Adamawa State, Nigeria
}

\author{
*11NA'ACHA, E; VANDI, P; CHESSED, G \\ Department of Zoology, School of Pure and Applied Sciences, \\ Modibbo Adama University of Technology, Yola, Nigeria \\ $+2348166576496,+2348055369298$ \\ nachae25@gmail.com
}

\begin{abstract}
Intestinal parasitic infections constitute a global health burden causing clinical morbidity. Parasitic protozoa and helminthes are responsible for some of the most devastating and prevalent diseases of human. The study was conducted to determine the prevalence of intestinal parasites among patients attending Federal Medical Center and Specialist Hospital Yola. A total of 438 stool specimens was collected randomly from the patients (204 male and 234 female) and examined by saline wet mount procedure and formalin-ether concentration technique. $155(35.4 \%)$ patients were found to be positive for intestinal parasites giving a breakdown of male, $70(34.3 \%)$ and female, $85(36.3 \%)$. There was no statistical difference in the infection between the genders. Ten parasites species, namely Ascaris lumbricoides, Schistosoma mansoni, Ancylostoma duodenale, Strongyloides stercoralis, Fasciola hepatica, Hymenolepis nana, Enterobius vermicularis, Entamoeba histolytica, Entamoeba coli, and Giardia lamblia were observed in the stool samples. The distribution of species in relation to gender shows that the male participant had E. histolytica $45(54.9 \%)$ followed by $A$. lumbricoides 19 (23.2\%), E. coli, 11 (13.4\%), S. mansoni 3 (3.7\%), G. lamblia 2(2.5\%), A. duodenale $1(1.2 \%)$ and $E$. vermicularis $1(1.2 \%)$. In the female participants, E. histolytica has the highest with $43(44.8 \%)$ followed by A. lumbricoides 20 (20.8\%), E. coli, 9 (9.4\%), S. mansoni 9 (9.4\%), A. duodenale 7(7.3\%), G. lamblia 3(3.1\%), H. nana 2(0.8\%) while $F$. hepatica has the least of $1(1.0 \%)$ The prevalence of intestinal parasites could be attributed to ignorance, exposure factors and negligence to prevention measures. Public enlightenment should be embarked upon $\odot$ JASEM
\end{abstract}

https://dx.doi.org/10.4314/jasem.v21i3.4

Keywords: Ascaris lumbricoides, Ancylostoma duodenale, Entamoeba histolytica, and Giardia lamblia.

A parasite is an organism that is entirely dependent on another organism refers to as its host, for all its metabolic requirements. Usually, parasite lives in or on the body or cells of the host, which usually caused harm to some extent by the association or may cause death. Human intestinal parasite are organisms that live inside the small or large intestine of human, and have several adaptations that ensures their survival in their host (Brumpt, 1996). Intestinal helminthes and protozoan parasites are major public health problems in developing countries (Lwambo et al., 1999; Handzel et al., 2003). Numerous studies have shown that the incidence of intestinal parasites may approach $99 \%$ in developing countries. Parasitic protozoa and helminthes are responsible for some of the most devastating and prevalent diseases of human. These infections have common characteristics. They are highly endemic in populations with low socio-economic status, poverty, illiteracy, lack of access to potable water, hot and humid tropical climate and poor hygiene, favouring larval skin penetration and oral-faecal transmission (Ravdin, 1995; Sayyari et al., 2005; Bethony et al., 2006). The infective stage of the intestinal protozoans (Entamoeba histolytica, Girdia lamblia, and
Balantidium coli) and some parasitic helminthes are the cysts, which usually get into the human body either through drinking contaminated water, food, fruit, vegetables, to mention a few. The parasites are important causal agents of gastrointestinal disorders such as diarrhea, dysentery, vomiting, lack of appetite, haematuria, abdominal distension and sometimes mentally related disorders (Bethony et al., 2006). Moreover, heavy chronic infections with Ascaris lumbricoides and hookworms (Ancylostoma duodenale or Necator americanus) may cause malnutrition and anaemia in high risk groups (Albonico et al., 1998; Awasti et al., 2003).

Intestinal parasitic infection can be controlled through the maintenance of proper personal hygiene, creating awareness to the people on the factors associated with the diseases. The study was conducted to determine the species and prevalence of human intestinal parasites among patients attending Federal Medical Center and Specialist Hospital Yola, Adamawa state.

\section{MATERIALS AND METHOD}

Study Area: The study was conducted in Federal Medical Center and Specialist Hospital in Yola, 
Adamawa State, Nigeria. Adamawa is one of the largest states of Nigeria and occupies about 36,917 square kilometers. Macroscopic examination of faecal sample was carried out to examine the consistency, colour, odour and presence of blood, mucus, adult and segment of intestinal helminthes (Arora and Brij, 2010). Saline wet mount procedure was carried out, with the aid of a dropper, a drop of physiological saline was placed on a clean slide using an applicator stick, a small portion of the stool was mixed with the normal saline drop by drop until a homogenous mixture was obtained. This was covered with a cover slip and mounted on the microscopy and examined.

Procedure: Formalin-ether concentration techniques was carried out, half teaspoon of faeces was thoroughly mixed in $10 \mathrm{ml}$ of water and strained through two layers of gauze in a funnel. The filtrate was centrifuged at 2,000rpm for 2 minutes. The supernatant was discarded and the sediment was resuspended in $10 \mathrm{ml}$ of physiological saline. It was again centrifuged and the supernatant was discarded. The sediment is re-suspended in $7 \mathrm{ml}$ of formalin saline and allowed to stand for 10 minutes or longer for fixation. To this was added $3 \mathrm{ml}$ of ether. The tube was stoppered and shaken vigorously to mix. Then the stopper was removed and the tube was centrifuged at 2,000rpm for 2 minutes. The tube was allowed to rest in a stand. Four layers become visible; the top layer consists of ether, second is a plug of debris, and third is a clear layer of formalin saline and the fourth is sediment. The plug of debris is detached from the side of the tube with the aid of a glass rod and the liquid is poured off leaving a small amount of formalin saline for suspension of the sediment. It is poured on a clean glass slide, covered with cover slip and examined under microscope. Ether dissolves faecal fats and formalin fixes the parasites and removes faecal odour. The risk of laboratory acquired infection from faecal organism is minimized because organisms are killed by formalin solution.

Ethics Statement: Ethical clearance to conduct the study was obtained from the Medical Centre Ethical committee; Oral consent was sought and obtained from some study participants who participated in the study after explaining the purpose and objectives of the study.

Statistical Analysis: Data was analyzed using SPSS version 17. Chi-square was used to analyze the variables.

\section{RESULTS AND DISCUSION}

A total of 438 samples were subjected for examination, Females had the highest with 234
(53.4\%), while Males had 204 (46.7\%). Infected samples were 155 with a prevalence rate of $35.4 \%$. Female had the highest participation of $85(53.3 \%)$ while male had $70(46.7 \%)$ though it was not statistically significance $(\mathrm{p}>0.05)$. The prevalence rate according to educational level shows that the highest prevalence rate was the participant with No formal education with $47(51.6 \%)$ this was followed by the participant who had primary education 34 $(42.5 \%)$ and tertiary education with 34 (29.8\%). Secondary education had $29(27.9 \%)$, while under care recorded $8(23.5 \%)$. The least prevalence was recorded in others with $3(20.0 \%)$, this were those whose educational level was not indicated in the questionnaire. Statistically there was significance difference in the prevalence of intestinal parasites by educational level $(\mathrm{p}<0.05)$. The age group 40-49 years had the highest rate of infection of 19(46.3\%), followed by $20-29$ years with $52(40.3 \%), 50 \geq$ years with 14 (37.8\%), 30-39 years with 29 (31.9\%), 10-19 years with $24(31.6 \%)$, the least was recorded in $0-9$ years with 17 (26.6\%), the difference in the prevalence rate was not statistically significant $(\mathrm{p}$ $>0.05$ ). (Table 1)

Ten parasites, namely Ascaris lumbricoides, Schistosoma mansoni, Ancylostoma duodenale, Strongyloides stercoralis, Fasciola hepatica, Hymenolepis nana, Enterobius vermicularis, Entamoeba histolytica, Entamoeba coli, and Giardia lamblia were observed in the stool samples of the participants. The distribution of species in relation to gender shows that the male participant had $E$. histolytica 45 (54.9\%) followed by A. lumbricoides 19(23.2\%), E. coli, 11 (13.4\%), S. mansoni 3 (3.7\%), G. lamblia 2(2.5\%), A. duodenale 1(1.2\%) and E. vermicularis $1(1.2 \%)$. In the female participants, $E$. histolytica has the highest with $43(44.8 \%)$ followed by A. lumbricoides 20 (20.8\%), E. coli, 9 (9.4\%), S. mansoni 9 (9.4\%), A. duodenale 7(7.3\%), G. lamblia $3(3.1 \%), H$. nana $2(0.8 \%)$ while $F$. hepatica has the least of $1(1.0 \%)$ (Table 2$)$

The distribution of species in relation to education shows that primary has the highest $E$. histolytica with $24(53.7 \%)$ while the least parasite species were; $S$. mansoni, G. lamblia, F. hepatica, and S. stercoralis having $1(2.4 \%)$ each, in primary, secondary has $A$. duodenale $1(2.4 \%)$ and S. stercoralis $1(2.4 \%)$ and tertiary has A. duodenale 1(2.4\%). (Table 3)

The distribution of species in relation to age group shows that 30-39 years has the highest of $E$. histolytica with $18(54.5 \%)$ while the least parasite species were; $S$. stercoralis and Hymenolepis nana in 20-29 years with $1(1.5 \%)$ each. (Table 4$)$

The data obtained from stool sample analysis were subjected to statistical test using chi-square $\left(\mathrm{X}^{2}\right)$. The level of significance was $\mathrm{p}<0.05$. 
Table 1: Prevalence of Intestinal Parasites among Patients Attending Federal Medical Center Yola and Specialist Hospital Jimeta, in relation to Gender, Educational level and Age

\begin{tabular}{|c|c|c|c|}
\hline Parameters & $\begin{array}{l}\text { No. } \\
\text { examined } \\
\mathrm{n} \quad(\%)\end{array}$ & $\begin{array}{l}\text { No. } \\
\text { infected } \\
\mathrm{n} \quad(\%)\end{array}$ & $\begin{array}{l}\text { Not } \\
\text { infected } \\
\mathrm{n} \quad(\%)\end{array}$ \\
\hline \multicolumn{4}{|l|}{ Gender } \\
\hline Male & 204(46.6) & $70(34.3)$ & $134(65.7)$ \\
\hline Female & $234(53.4)$ & $85(36.3)$ & $149(63.7)$ \\
\hline Total & $438(100.0)$ & $155(35.4)$ & $283(64.6)$ \\
\hline \multicolumn{4}{|l|}{ Education } \\
\hline Under care & $34(7.8)$ & $8(23.5)$ & $26(76.5)$ \\
\hline Primary & $80(18.3)$ & $34(42.5)$ & $46(57.5)$ \\
\hline Secondary & $104(23.7)$ & $29(27.9)$ & $75(72.1)$ \\
\hline Tertiary & $114(26.1)$ & $34(29.8)$ & $80(70.2)$ \\
\hline Non formal & $91(20.8)$ & $47(51.6)$ & $44(48.4)$ \\
\hline Others & $15(3.4)$ & $3(20.0)$ & $12(80.0)$ \\
\hline Total & $438(100.0)$ & $155(35.4)$ & $283(64.6)$ \\
\hline \multicolumn{4}{|l|}{ Age } \\
\hline $0-9$ & $64(14.6)$ & $17(26.6)$ & $47(73.4)$ \\
\hline $10-19$ & $76(17.4)$ & $24(31.6)$ & $52(68.4)$ \\
\hline $20-29$ & $129(29.5)$ & $52(40.3)$ & $77(59.7)$ \\
\hline $30-39$ & $91(20.8)$ & $29(31.9)$ & $62(68.1)$ \\
\hline $40-49$ & $41(9.4)$ & $19(46.3)$ & $22(53.7)$ \\
\hline $50 \geq$ & $37(8.5)$ & $14(37.8)$ & $23(62.2)$ \\
\hline Total & $438(100.0)$ & $155(35.4)$ & $283(64.6)$ \\
\hline
\end{tabular}

Table 2: Distribution of single Infection among patients attending Federal Medical Centers and Specialist Hospital by Gender and type of parasites species

\begin{tabular}{|c|c|c|c|c|c|c|c|c|c|c|c|c|}
\hline Gender & $\begin{array}{l}\text { No. infected } \\
\mathrm{n}(\%)\end{array}$ & $\begin{array}{l}\text { A. } l \\
\mathrm{n}(\%)\end{array}$ & $\begin{array}{l}\text { S. } m \\
\text { n (\%) }\end{array}$ & $\begin{array}{l}\text { A. } d \\
\text { n }(\%)\end{array}$ & $\begin{array}{l}\text { S. } s \\
\text { n }(\%)\end{array}$ & $\begin{array}{l}F . h \\
\text { n }(\%)\end{array}$ & $\begin{array}{l}\text { H. } n \\
\text { n (\%) }\end{array}$ & $\begin{array}{l}\text { E. v } \\
\text { n }(\%)\end{array}$ & $\begin{array}{l}E . h \\
\text { n }(\%)\end{array}$ & $\begin{array}{l}\text { E.coli } \\
\text { n (\%) }\end{array}$ & $\begin{array}{l}G . l \\
\mathrm{n}(\%)\end{array}$ & $\begin{array}{l}\text { Total } \\
\text { n (\%) }\end{array}$ \\
\hline Male & $70(45.2)$ & $19(23.2)$ & $3(3.7)$ & $1(1.2)$ & $0(0.0)$ & $0(0.0)$ & $0(0.0)$ & $1(1.2)$ & $45(54.9)$ & $11(13.4)$ & $2(2.5)$ & $82(100)$ \\
\hline Female & $85(54.8)$ & $20(20.8)$ & $9(9.4)$ & $7(7.3)$ & $2(2.1)$ & $1(1.0)$ & $2(0.8)$ & $0(0.0)$ & $43(44.8)$ & $9(9.4)$ & $3(3.1)$ & $96(100.0)$ \\
\hline Total & $155(100)$ & $39(21.9)$ & $12(6.7)$ & $8(4.5)$ & $2(1.1)$ & $1(0.6)$ & $2(1.1)$ & $1(0.6)$ & $88(49.4)$ & $20(11.2)$ & $5(2.8)$ & $178(100)$ \\
\hline
\end{tabular}

$\chi_{\text {cal }}^{2}=11.8$

$\mathrm{Tab}=18.31, \mathrm{df}=10, \mathrm{p}>0.05$

Table 3: Distribution of single Infection among patients attending Federal Medical Centers and Specialist Hospital by Educational level and type of parasites species

\begin{tabular}{|c|c|c|c|c|c|c|c|c|c|c|c|c|}
\hline Education & $\begin{array}{l}\text { No. infected } \\
\mathrm{n}(\%)\end{array}$ & $\begin{array}{l}\text { A. } l \\
\text { n }(\%)\end{array}$ & $\begin{array}{l}\text { S. } m \\
\text { n }(\%)\end{array}$ & $\begin{array}{l}\text { A. } d \\
\text { n }(\%)\end{array}$ & $\begin{array}{l}S . s \\
\text { n }(\%)\end{array}$ & $\begin{array}{l}F . h \\
\text { n }(\%)\end{array}$ & $\begin{array}{l}H . n \\
\text { n }(\%)\end{array}$ & $\begin{array}{l}\text { E. v } \\
\text { n }(\%)\end{array}$ & $\begin{array}{l}\text { E. } h \\
\text { n }(\%)\end{array}$ & $\begin{array}{l}\text { E.coli } \\
\text { n (\%) }\end{array}$ & $\begin{array}{l}\text { G. } l \\
\text { n }(\%)\end{array}$ & $\begin{array}{l}\text { Total } \\
\text { n (\%) }\end{array}$ \\
\hline U/care & $8(5.2)$ & $2(25.0)$ & $0(0.0)$ & $0(0.0)$ & $0(0.0)$ & $0(0.0)$ & $0(0.0)$ & $0(0.0)$ & $5(62.5)$ & $0(0.0)$ & $1(12.5)$ & $8(100.0)$ \\
\hline Primary & $34(21.9)$ & $7(17.0)$ & $1(2.4)$ & $0(0.0)$ & $1(2.4)$ & $1(2.4)$ & $2(4.9)$ & $0(0.0)$ & $24(53.7)$ & $6(14.6)$ & $1(2.4)$ & $41(100.0)$ \\
\hline $\begin{array}{l}\text { Second. } \\
\text { Tertiary }\end{array}$ & $\begin{array}{l}29(18.7) \\
34(21.9)\end{array}$ & $\begin{array}{l}9(23.1) \\
10(24.4)\end{array}$ & $\begin{array}{l}3(7.7) \\
2(4.9)\end{array}$ & $\begin{array}{l}1(2.6) \\
1(2.4)\end{array}$ & $\begin{array}{l}1(2.6) \\
0(0.0)\end{array}$ & $\begin{array}{l}0(0.0) \\
0(0.0)\end{array}$ & $\begin{array}{l}0(0.0) \\
0(0.0)\end{array}$ & $\begin{array}{l}0(0.0) \\
0(0.0)\end{array}$ & $\begin{array}{l}21(53.9) \\
20(48.8)\end{array}$ & $\begin{array}{l}4(10.3) \\
8(19.5)\end{array}$ & $\begin{array}{l}0(0.0) \\
0(0.0)\end{array}$ & $\begin{array}{l}39(100.0) \\
41(100.0)\end{array}$ \\
\hline Non form. & $47(30.4)$ & $11(23.4)$ & $6(12.8)$ & $6(12.8)$ & $0(0.0)$ & $0(0.0)$ & $0(0.0)$ & $0(0.0)$ & $19(40.4)$ & $2(4.3)$ & $3(6.4)$ & $47(100.0)$ \\
\hline $\begin{array}{l}\text { Others } \\
\text { Total }\end{array}$ & $\begin{array}{l}3(1.9) \\
155(100)\end{array}$ & $\begin{array}{c}0(0.0) \\
39(21.9)\end{array}$ & $\begin{array}{l}0(0.0) \\
12(6.7)\end{array}$ & $\begin{array}{l}0(0.0) \\
8(4.5)\end{array}$ & $\begin{array}{l}0(0.0) \\
2(1.1)\end{array}$ & $\begin{array}{l}0(0.0) \\
1(0.6)\end{array}$ & $\begin{array}{l}0(0.0) \\
2(1.1)\end{array}$ & $\begin{array}{l}1(50.0) \\
1(0.6)\end{array}$ & $\begin{array}{l}1(50.0) \\
88(49.4)\end{array}$ & $\begin{array}{l}0(0.0) \\
20(11.2 \\
)\end{array}$ & $\begin{array}{l}0(0.0) \\
5(2.8)\end{array}$ & $\begin{array}{l}2(100.0) \\
178(100)\end{array}$ \\
\hline
\end{tabular}

$\chi_{\text {cal }}^{2}=141.33, \mathrm{Tab}=67.50, \mathrm{df}=50, \mathrm{p}>0.05$ 
Table 4: Distribution of single Infection among patients attending Federal Medical Centers and Specialist Hospital by Age and type of parasites species

\begin{tabular}{|c|c|c|c|c|c|c|c|c|c|c|c|c|}
\hline Age & $\begin{array}{l}\text { No. Infected } \\
\text { n }(\%)\end{array}$ & $\begin{array}{l}\text { A. } l \\
\mathrm{n}(\%)\end{array}$ & $\begin{array}{l}\text { S. } m \\
\text { n }(\%)\end{array}$ & $\begin{array}{l}\text { A. } d \\
\mathrm{n}(\%)\end{array}$ & $\begin{array}{l}\text { S. } s \\
\text { n }(\%)\end{array}$ & $\begin{array}{l}F . h \\
\text { n }(\%)\end{array}$ & $\begin{array}{l}\text { H. } n \\
\text { n }(\%)\end{array}$ & $\begin{array}{l}\text { E. } v \\
\mathrm{n}(\%)\end{array}$ & $\begin{array}{l}\text { E. } h \\
\text { n }(\%)\end{array}$ & $\begin{array}{l}\text { E.coli } \\
\text { n }(\%)\end{array}$ & $\begin{array}{l}\text { G. } l \\
\mathrm{n}(\%)\end{array}$ & $\begin{array}{l}\text { Total } \\
\mathrm{n}(\%)\end{array}$ \\
\hline $0-9$ & $17(11.0)$ & $6(33.3)$ & $0(0.0)$ & $0(0.0)$ & $0(0.0)$ & $1(5.6)$ & $0(0.0)$ & $0(0.0)$ & $9(50.0)$ & $1(5.6)$ & $1(5.6)$ & $18(100.0)$ \\
\hline $\begin{array}{l}10-19 \\
20-29\end{array}$ & $\begin{array}{l}24(15.5) \\
52(55.9)\end{array}$ & $\begin{array}{l}5(21.7) \\
14(20.6)\end{array}$ & $\begin{array}{l}0(0.0) \\
7(10.3)\end{array}$ & $\begin{array}{l}1(4.4) \\
6(8.8)\end{array}$ & $\begin{array}{l}1(4.4) \\
1(1.5)\end{array}$ & $\begin{array}{l}0(0.0) \\
0(0.0)\end{array}$ & $\begin{array}{l}1(4.4) \\
1(1.5)\end{array}$ & $\begin{array}{l}0(0.0) \\
0(0.0)\end{array}$ & $\begin{array}{l}12(52.2) \\
29(42.7)\end{array}$ & $\begin{array}{l}3(13.0) \\
7(10.3)\end{array}$ & $\begin{array}{l}0(0.0) \\
3(4.4)\end{array}$ & $\begin{array}{l}23(100.0) \\
68(100.0)\end{array}$ \\
\hline $30-39$ & $29(18.7)$ & $7(21.2)$ & $3(9.1)$ & $0(0.0)$ & $0(0.0)$ & $0(0.0)$ & $0(0.0)$ & $0(0.0)$ & $18(54.5)$ & $5(15.2)$ & $0(0.0)$ & $33(100.0)$ \\
\hline $40-49$ & $19(12.3)$ & $4(17.4)$ & $2(8.7)$ & $1(4.4)$ & $0(0.0)$ & $0(0.0)$ & $0(0.0)$ & $0(0.0)$ & $12(52.2)$ & $4(17.4)$ & $0(0.0)$ & $23(100.0)$ \\
\hline $\begin{array}{l}50 \geq \\
\text { Total }\end{array}$ & $\begin{array}{l}14(9.0) \\
155(100.0)\end{array}$ & $\begin{array}{c}3(23.1) \\
39(21.9)\end{array}$ & $\begin{array}{l}0(0.0) \\
12(6.7)\end{array}$ & $\begin{array}{l}0(0.0) \\
8(4.5)\end{array}$ & $\begin{array}{l}0(0.0) \\
2(1.1)\end{array}$ & $\begin{array}{l}0(0.0) \\
1(0.6)\end{array}$ & $\begin{array}{l}0(0.0) \\
2(1.1)\end{array}$ & $\begin{array}{l}1(7.7) \\
1(0.6)\end{array}$ & $\begin{array}{l}8(61.5) \\
88(49.4)\end{array}$ & $\begin{array}{l}0(0.0) \\
20(11.2)\end{array}$ & $\begin{array}{l}1(7.7) \\
5(2.8)\end{array}$ & $\begin{array}{l}13(100.0) \\
178(100)\end{array}$ \\
\hline
\end{tabular}

$\chi_{\text {cal }}^{2}=38.06, \mathrm{Tab}=67.50, \mathrm{df}=50, \mathrm{p}>0.05$

Key: A.l-Ascaris lumbriodes, S.m-Schistosoma mansoni, A.d-Ancylostoma duodenalum, S.s- Strongyloides stercoralis, F.h- Fasciola hepatica, H.n- Hymenolepis nana, E.v- Enterobius vermicularis, E.h- Entamoeba histolytica, G.l- Giardia lamblia, Second- Secondary, U/care- Under care.

The overall result of the investigation on the prevalence of intestinal parasites among patients attending two Medical Centers in Yola, Adamawa State was $35.4 \%$; this study appears high when compared with some reported work from previous studies in the country as shown by Opara et al. (2007), who reported a value of $21.1 \%$ in Owerri, Imo State and Ibrahim et al. (2014), who reported $17.5 \%$ among patients attending University of Maiduguri Teaching Hospital, Nigeria; but the prevalence is almost similar with $37.3 \%$ reported by Anosike et al. (2006) in a central Nigerian rural community and $33.1 \%$ prevalence rate reported by Okeniyi et al. (2005) among semi-urban Nigerians. The similarity in the prevalence rate could be that the research was carried out under similar ecological conditions of temperature, relative humidity and rainfall (Onwuliri et al., 1993), which contribute to providing a favourable condition for parasites to thrive in those areas. The prevalence rate observed in this study could be due to the fact that a great number of people consume fruits without washing or proper washing of fruits and vegetables before consumption. Vegetables and meat, if not properly cooked, some parasites in their cyst form are able to withstand a certain level of heat, when consumed, one can be infected. This is because people defecate at nearby bushes where those vegetables are grown or the use of animal dungs as manure could aid in transfer of cysts. Crompton, (1999), reported that the high prevalence observed in his study was attributed to poor environment and personal hygiene, shortage of good water supply and indiscriminate defecation. This may be applicable in our study.

Prevalence with respect to gender showed no significant difference $(p>0.05)$, implying that the difference in males and females only occurred by chance, however, male prevalence rate $70(34.3 \%)$ and female prevalence rate $85(36.3 \%)$ corroborates with other reports by Ibrahim et al. (2014); Obiukwu et al. (2008); and Mazigo et al. (2010); they reported that both males and females have the same chances of being infected by these parasites. Results reported by Adeyeba and Akinlabi (2002) and Baldo et al. (2004) disagrees with this study, it showed that infection rates for intestinal parasites were higher in males than females. However Agbolade et al. (2004) and Taiwo and Agbolade (2000) showed from their results that helminthic infections were not sex dependent. Such predominance in infections rates is likely to be a reflection of different behavior between the two groups (Hotez et al., 2006). In a study in Cameroon, it was found that the higher prevalence of human intestinal protozoans in female was attributed to the fact that women usually eat unwashed fruits and vegetables or unboiled salad which may be contaminated with protozoan cyst (Mbuh et al., 2010).

The prevalence rate according to educational level showed that the highest prevalence rate was the participant with no formal education $47(51.6 \%)$ and the lowest prevalence rate was under care $8(23.5 \%)$ and others $3(20.0 \%)$, statistically there was significant difference $(\mathrm{p}<0.05)$, this result disagrees with the result recorded by Kia et al. (2008). Reasons could be because the children whose age are less than 2 years which were referred to as under care are less susceptible to the mode of transmission, and others were those whose educational level was not indicated. The high prevalence rate among the non-formal study participants could be as result of ignorance about the mode of transmission.

The age group 40 - 49 years, recorded highest prevalence value of $46.3 \%$ while lowest prevalence value was $26.6 \%$ among the age group $0-9$, statistically there was no significant difference $(\mathrm{p}>$ 0.05). This study agrees with the result of Mazigo et al. (2010) and Kia et al. (2008) but disagrees with the finding of Ngele, (2012) on the prevalence of 
intestinal protozoan parasites among the undergraduate students of Akanu Ibiam Federal Polytectnic Unwana, Ebonyi State. The high prevalence rate within the age group could be as result of exposure to the mode of transmission and carelessness on the preventive measures.

Helminths: Ascaris lumbricoides was one of the most common intestinal parasite in this study, as in other studies, because the worm is remarkably infectious and usually versatile (WHO, 2002; Bello et al., 1992). The well-protected eggs of Ascaris can withstand drying and can survive for very lengthy periods (Mordi and Ngwodo, 2007). The low prevalence of Strongyloides stercoralis in faeces $1.1 \%$ agreed with previous studies by Ijagbone and Olagunji, (2006), Dash et al. (2010), who recorded a value of $0.36 \%$. Ibrahim et al. (2014) reported $2.9 \%$ prevalence. Reason for low prevalence observed in most studies may be connected to its vulnerability to adverse environmental conditions hence its alternate mode of infection.

Protozoans: In this study, Entamoeba histolytica had a prevalence of $49.4 \%$. Studies done elsewhere in Nigeria reported lower prevalence values. For instance, Anosike et al. (2002), reported a value $4.0 \%$, and in other countries Mazigo et al. (2010), recorded a value of $13.6 \%$, and Kia et al. (2008), reported the value of $1.2 \%$ but Ibrahim et al. (2014), reported a high prevalence rate of $40 \%$. Other protozoa that were observed in this study were $E$. coli $(11.2 \%)$ and Giardia lamblia $(2.8 \%)$. The prevalence of the two protozoans appear low, when compared with the findings of Oguoma et al. (2008), who recorded a prevalence of $36.0 \%$ and $25.0 \%$, for $E$. coli and G. lamblia respectively. The high prevalence of $E$. histolytica could be as a result of poor water supply. Buying water from truck pushers and drinking directly from their gallon without boiling could lead to infection with the parasites observed in the study. Most times those gallons are not washed or properly washed.

Conclusion: The prevalence of intestinal parasites was high when compare to other places in Nigeria. Consumption of contaminated food and water, fruits, vegetables, lack of sanitation and personal hygiene could be possible cause of infection with intestinal parasites. Eating fruits without washing of hands after visiting the toilet or handshake could lead to infection with parasites. Yola is an urban area with educated people; the prevalence rate could be due to negligence, inadequate water supply and lack of regular deworming.

It is recommended that efforts should be made by World Health Organization (WHO), NonGovernmental Organizations (NGOs), Federal and State Government to enlighten the public on intestinal parasites. The mode of transmission should be emphasized during the enlightenment. Intervention strategy should be design and implemented including provision of adequate and safe water supply, encourage the public on regular deworming, health education on personal hygiene and sanitation of their environment.

Acknowledgements: I am grateful to God Almighty for seeing me through, I extend my special thanks to all the staff of microbiology laboratory department, Federal Medical Center Yola, and all the staff of microbiology laboratory department, Specialist Hospital Jimeta, for their assistance during sample collection and examination.

\section{REFERENCES}

Adeyeba, O.A. and Akinlabi, A. (2002). Intestinal parasitic infections among school children in a rural community, Southwest Nigeria. Nigerian Journal of Parasitology. 23, 11-18.

Agbolade, O.M.; Akinboye, O.M. and Awolaja. (2004). Intestinal helminthiasis and Urinary Schistosomiasis in some villages of Ijebu North, Ogun State, Nigeria. African Journal of Biotechnology. 3: 206-209.

Albonico, M.; Stolfzfus, R.J. and Savioli L. (1998). Epidermiological evidence for a differential effect of hookworm species, Anclostoma duodenalis or Necator americanus, on iron status of children. International Journal of Epidermiology. 27, 530-537.

Albonico, M.; bickle, Q.; Ramsan, M.; Montresor, A.; savioli, L. and Taylor, M. (2003). Efficiency of Mebendazole and Levamisole alone or in combination against intestinal nematode infections after repeated targeted Mebendazole treatment in Zanzibar. Bulletin of the World Health Organisation. 81, 343-352.

Anosike, J. C.; Chighana, J. I.; Nwoke, B. E. B.; Ezike, M. N.; Dike, M. U.; Ukaga, C. N.; Okereke, M. S. C. and Ajero, C. M. U. (2006). A survey of intestinal parasites among students of post primary institution in Imo State. 28th annual conference Abstract (63). Nigerian, Society for Parasitology. 20: 74.

Arora, D. R. and Brij, B. A. (2010). Diagnostic Procedures. Medical Parasitology 3rd edition. CBS Publisher, New Delhi, 29-30 pp.

Awasti, S.; Bundy D. A. P. and Savioli, L. (2003). Helminthic infections. Brazil Medical Journal 327: 431-433. 
Baldo, E. T.; Belizairo, V. Y.; Deleon, W. U.; Kong H. H. and Chung, D. I. I. (2004). Infection status of intestinal parasites in children living in residential institutions in Metro Manila, the Philippines. Korean Journal of Parasitology, 42 (2): 67-70.

Bethony, J.; Brooker, S.; Albanico, M.; Geiger, S. M.; Louker, A.; Diemert, D. and Hotez, P. J.(2006). Soil-transmitted helminth infections; Ascaris, Trichuriasis and hookworm. Lancet 367: 1521.

Bethony, J.; Chen, J. and Lin, S. (2002). Emerging patterns of hookworm infection: influence of aging on the intensity of Necator infection in Hainan Province, People's Republic of China. Clinical Infectious Disease. 35, 1336-1344.

Brumpt, L. M. (1996). Parasitology (First edition), Cambridge University Press, International. U.K. 184.

Crompton, D. W. T. (1999). How much human helminthiasis is there in the world? Journal of Parasitology, 85: 397-403.

Dash, N.; Mansour, A.; Khurshid, A. and Debedatta, P. (2010). Prevalence of intestinal parasitic infections in Sharjah, United Arab Emirates. Human Parasitic Diseases. 21-24.

Handzel, T.; Karanja, D. M.; Addiss, D. G.; Hightower, A. W.; Rosen, D. H.; Colley, D. G.; Andove, J.; Slutsker, L. and Evansecor, W. (2003). Geographic distribution of Schistosomiasis and soil-transmitted helminthes in West Kenya: Implication for anthelminthic mass treatment. American Journal of Tropical Medicine and Hygiene. 69: 318-323.

Hotez, P. J.; Bundy, D. A. P. and Beegle, K. (2006). Helminth infections. Soil - Transmitted infection and Schistosomiasis. The International Bank for Reconstruction and Development/ The World Bank, 2006.

Ibrahim, M. M.; Askira, M. U. and Tom, M. I. (2014) Intestinal Parasitic Infections among Patients attending a Tertiary Health Institution in Northeastern Nigeria. American Journal of Research Communication, 2 (6): 88-96.

Ijagbone, I. F. and Olagunju, T. F. (2006). Intestinal helminth parasites in school children in Iragbiji, Boripe Local Government, Osun State. Africa Journal of Biomedical Research, 9. 63-69.

Kia, E. B.; Hosseini, M.; Nilforoushan, M. R.; Meamar, A. R. and Rezaeian, M. (2008). Study of intestinal protozoan parasites in rural inhabitants of Mazandaran Province, Northern Iran. Iranian Journal of parasitology. 3. 21-25.

Lwambo, N. J. S.; Siza, J. E.; Brooker, S.; Bundy, D. A. P. and Guyatt, H. (1999). Pattern of concurrent hookworm infection and Schistosomiasis in school children in Tanzania. Transactions of Royal Society of Tropical Medicine and Hygiene. 93, 497-502.

Mazigo, H. D.; Ambrose, E. E.; Zinga, M.; Bahemana, E.; Mnyone, L. L.; Kweka, E. J. and Heukelbach, J. (2010). Prevalence of intestinal parasitic infections among patients attending

Bugando Medical Center in Mwanza, north-western Tanzania: a retrospective study. Journal of Health Research 2 - 7.

Mbuh, J. V.; Ntonifor, H. N. and Ojong, J. T. (2010). The incidence, intensity and host morbidity of human parasitic protozoan infections in gastrointestinal disorder outpatients in Buea Sub Division, Cameroon. Journal of Infection in Developing Countries, 4 38-43.

Mordi, R. M. and Ngwodo, P. O. A. (2007). A study of blood and gastro - intestinal parasites in Edo State. African Journal of Biotechnology, 6 (19): 2201-2207.

Ngele, K. K. (2012). The prevalence of intestinal protozoan parasites among the undergraduate studentsof Akanu Ibiam Federal Polytechnic, Unwana, Ebonyi State. Abstract of Nigerian Journal of Parasitology, 3 (4) 876-878.

Obiukwu, M. O.; Umeanaeto, P. U.; Enenya, C. I. and Nwaorgu, G. O. (2008). Prevalence of gastrointestinal helminthes in school children in Mbaukwu, Anambra State. Nigeria Journal of Parasitology 29 (1): 15-19.

Oguoma, V. M.; Anyasodor, A. E. and Mbata, T. I. (2008). Prevalence of intestinal protozoan parasites among children aged 5-12 years in Owerri Metropolis, Southeastern Nigeria.Tropical Journal of Health Science, 15 (2): 43-48.

Okeniyi, J. A. O.; Ogunlesi, O. A.; Oyelami, O. A. and Oyedeji, G. A. (2005). Asymptomatic intestinal parasitosis among semi-urban Nigerian children. The Internet Journal of Epidemiology, 2: 2 .

Onwuliri, C. O. E.; Anosike, J. C.; Nkem, C. N. and Payne, V. K. (1993). The ecology of animal parasitic nematodes in endemic areas of Jos, Nigerian Applied Parasitology (In Press). 
Opara, F. N.; Udoye, A. A.; Okere, P. U.; Osuala, F. O. U. and Iwuala, M. O. E. (2007). Infections in primary school children in Owerri municipality, Imo State. Journal of Parasitic Disease 31: (1) 44- 48.

Ravdin, J. I. (1995). Amoebiasi. Clinical Infectious Disease 20, 1453-1466.

Sayyari, A. A.; Imanzadeh, F.; Bagheri, Y. S. A.; Karami, H. and Yaghoobi, M. (2005). Prevalence of intestinal parasitic infection in Islamic Republic of Iran. East Mediterranean Health Journal, 11. 377-383.
Taiwo and Agbolade, (2000). Intestinal helminthiasis among school children in Oru, Ogun State, Nigeria. Nigeria Journal of Sciences. 34, 283286.

WHO (2002). Estimates of the disease burden due to soil-transmitted helminthiasis: Prevalence and control of Schistosomiasis and soil transmitted helminthiasis. Technical Report Series. 912: 2-3. 